\title{
CONSUMER PROTECTION FOR FINANCIAL INCLUSION IN LOW AND MIDDLE INCOME COUNTRIES: BRIDGING REGULATOR AND ACADEMIC PERSPECTIVES
}

\author{
Seth Garz \\ Xavier Giné \\ Dean Karlan \\ Rafe Mazer \\ Caitlin Sanford \\ Jonathan Zinman \\ Working Paper 28262 \\ http://www.nber.org/papers/w28262 \\ NATIONAL BUREAU OF ECONOMIC RESEARCH \\ 1050 Massachusetts Avenue \\ Cambridge, MA 02138 \\ December 2020, Revised April 2021
}

When citing this paper, please use the following: Annu. Rev. Econ. 3, 2020: Submitted. DOI: 10.1146/annurev-financial-071020-012008. The views expressed herein are those of the authors and should not be attributed to the Bill \& Melinda Gates Foundation or the World Bank, its executive directors, the countries they represent, or the National Bureau of Economic Research.

NBER working papers are circulated for discussion and comment purposes. They have not been peer-reviewed or been subject to the review by the NBER Board of Directors that accompanies official NBER publications.

(C) 2020 by Seth Garz, Xavier Giné, Dean Karlan, Rafe Mazer, Caitlin Sanford, and Jonathan Zinman. All rights reserved. Short sections of text, not to exceed two paragraphs, may be quoted without explicit permission provided that full credit, including $\odot$ notice, is given to the source. 
Consumer Protection for Financial Inclusion in Low and Middle Income Countries: Bridging Regulator and Academic Perspectives

Seth Garz, Xavier Giné, Dean Karlan, Rafe Mazer, Caitlin Sanford, and Jonathan Zinman

NBER Working Paper No. 28262

December 2020, Revised April 2021

JEL No. D11,D12,D18,D81,D82,D83,D9,G21,K23,K31,K42,O12

\section{ABSTRACT}

Markets for consumer financial services are growing rapidly in low and middle income countries and being transformed by digital technologies and platforms. With growth and change come concerns about protecting consumers from firm exploitation due to imperfect information and contracting as well as from their own decision-making limitations. We seek to bridge regulator and academic perspectives on these underlying sources of harm and five potential problems that can result: high and hidden prices, overindebtedness, post-contract exploitation, fraud, and discrimination. These potential problems span product markets old and new, and could impact micro- and macroeconomies alike. Yet there is little consensus on how to define, diagnose, or treat them. Evidence-based consumer financial protection will require substantial advances in theory and especially empirics, and we outline key areas for future research.

\author{
Seth Garz \\ Bill and Melinda Gates Foundation \\ Seth.Garz@gatesfoundation.org \\ Xavier Giné \\ The World Bank \\ 1818 H Street N.W. \\ Mail Stop MC 3-307 \\ Washington, D.C. 20433 \\ xgine@worldbank.org \\ Dean Karlan \\ Kellogg Global Hub \\ Northwestern University \\ 2211 Campus Drive \\ Evanston, IL 60208 \\ and CEPR \\ and also NBER \\ dean.karlan@gmail.com
}

\author{
Rafe Mazer \\ 1440 G St. NW \\ Suite 9142 \\ Washington, DC 20005-2001 \\ rmazer@poverty-action.org \\ Caitlin Sanford \\ 1440 G St. NW \\ Suite 9142 \\ Washington, DC 20005-2001 \\ caitlins@gmail.com \\ Jonathan Zinman \\ Department of Economics \\ Dartmouth College \\ 314 Rockefeller Hall \\ Hanover, NH 03755 \\ and NBER \\ jzinman@dartmouth.edu
}




\section{Introduction}

Markets for consumer financial services are growing and evolving rapidly in low and middle income countries (LMICs). Digital technologies and platforms in particular are fueling significant transformations to products, distribution, and business processes for financial services. Overall, from 2014 to 2017 the share of adults in LMICs depositing and borrowing at formal financial institution increased from 54 percent to 63 percent and 9 to 15 percent, respectively. Growth in digital finance is similarly rapid: the share of adults in LMICs using digital payments increased from 32 to 44 percent from 2014 to 2017, and as an example from Kenya, 13.6 percent of adults accessed a loan through digital channels in 2018 alone. ${ }^{2}$

Some of this growth has been accelerated by financial inclusion policies. For example, distributing cash transfers through debit cards in Mexico generated spillovers to retailers and non-poor households and substantially increased debit card adoption (Higgins 2020). In India, the central government mandated the opening of a bank account for every unbanked household through the Jan Dhan Yojana scheme in 2014; an estimated 80 percent of households now have an account.

These market changes and financial inclusion strategies have spurred policymakers, government regulators, and stakeholders in LMICs - who we will refer to collectively as "regulators"- to focus on consumer financial protection. Many LMIC consumers lack experience with formal financial services, much less fintech, and the experience of richer countries over the past several decades suggests that even relatively experienced consumers can be harmed by using financial services. Moreover, consumer harm can spill over to the macroeconomy (Mian and Sufi 2018).

We review academic research related to consumer financial protection with an eye toward bridging regulator and academic perspectives on key problems, viable solutions, and the most important open research questions. We focus on household credit, savings, and payments. Many of the issues and potential solutions we cover are equally relevant for insurance and entrepreneurial finance.

We organize our review around five key problems identified by regulators in LMICs: (1) High and hidden prices; (2) Overindebtedness; (3) Post-contract exploitation, with a focus on agents charging extra transaction fees, add-on of services without consent, and debt collection harassment; (4) Fraud; and, (5) Discrimination and disparate impacts on disadvantaged groups. ${ }^{3}$ We discuss each of these potential problems in four steps.

First, we describe the problem from the regulatory perspective, and discuss diagnostic challenges.

Second, we discuss the theoretical mechanisms that may underlie the problem and the existing empirical evidence (or lack thereof). We discuss what is known, and unknown, about specific market failures and consumer decision-making limitations (“decision failures," in our parallel—if uncharitable — shorthand) that may help explain the root cause of each problem. For more traditional sources of market failure, we discuss imperfect and incomplete information (typically regarding pricing and fees), externalities, and moral hazard by firms or fraudulent actors. For decision failures, we consider a broad set, including present bias, inattention, lack of financial literacy, limited learning, and scarcity (see also Agarwal,

\footnotetext{
${ }^{2}$ Statistics in this paragraph are from Demirguc-Kunt et al. (2015; 2017), FSD Kenya (2019), and Gubbins (2019).

${ }^{3}$ Relative to previous reviews of consumer financial protection (Campbell et al. 2011; Campbell 2016), we focus more on LMICs, on considering how behavioral industrial organization theory motivates rethinking regulatory goals and tactics, and on bridging regulator and academic perspectives to set research agendas. For reviews specific to the product markets we cover, see Karlan et al. (2014), Zinman (2015), and Suri (2017). For broader reviews of household finance see Agarwal et al. (2020) and Gomes et al. (forthcoming).
} 
Chomsisengphet, and Lim 2017; Beshears et al. 2018). Diagnosing specific decision and market failures is difficult, as the same behavior or outcome often can be explained with different theories. Such work is vitally important for policy because distinct theories often have radically different policy implications.

Third, we review regulatory and programmatic approaches to the problem, including both traditional approaches like restricting contract terms, mandating disclosures, and providing financial education, and newer approaches like outcomes-based regulation, prohibitions on deceptive and abusive advertising and other practices, and nudging. We focus on what is known and not known about the effectiveness of these approaches, stopping short in most cases of assessing efficiency (i.e., societal welfare) for two key reasons. First, we typically lack convincing empirical evidence on many of the inputs required for quantitative welfare analysis. Concretely, for example, assessing the efficiency of an interest rate cap requires quantitative estimates of the benefit to some from lower interest rates against the loss to others from not being able to borrow at all —and obtaining those estimates requires estimates of several underlying parameters that are difficult to identify accurately and precisely. Second, potential consumer decision failures substantially complicates welfare analysis (D. Bernheim and Taubinsky 2018). If someone is present-biased, for example, which "self" is used to calculate welfare, the current impatient self or the future planning self?

Lastly for each potential problem, we highlight key open research questions that should be addressed to improve regulator capacity for successful consumer protection policies.

Three key themes cut across the five problem areas and loosely correspond to the three key actors relevant for consumer protection: the consumer, the firm, and the government. The first is the empirical importance of consumer decision failures in driving consumer and market outcomes. We find compelling evidence of their importance for our first key problem - high and hidden prices - but for the remainder we have more questions than answers. The second theme relates to the validity of a fundamental premise of consumer protection policy: "Robust competition is the best single means for protecting consumer interests" (Muris 2002). Consumer protection regulators and researchers often overlook several bodies of theory on market and decision failures that question this premise (e.g., Rysman 2009; Heidhues and Köszegi 2018). However, these theories are largely untested empirically. A third cross-cutting theme relates to limited state capacity for regulation and its enforcement (Estache and Wren-Lewis 2009). ${ }^{4}$ Regulatory frameworks may be less developed in LMICs, although not by as much as commonly assumed (World Bank Group 2017). The World Bank Group (2017) documents substantial variation in consumer protection laws and regulatory practices across 124 countries, including 45 LMICs. LMICs are roughly as likely as higher income countries to conduct supervisory activities such as complaint data collection, mystery shopping, on-site inspections, although the legal basis for financial sector intervention tends to be weaker in LMICs. A cleaner legal slate actually could be an advantage if it helps leapfrog "legacy" issues with, for example, ineffective policy design, limited monitoring capacity, and jurisdictional fragmentation. These issues are particularly important to address in markets where nonbanks (e.g., fintechs) are emerging as competitors to traditional banks, and in markets like payments that span borders and/or have coordination problems like interoperability. Concerns about corruption often focus on LMICs but apply to richer countries as well. In short, limited state capacity is a concern for most consumer financial protection regulators around the world.

Another cross-cutting theme is the increasingly important challenge of outcome measurement, given the growth of consumer outcomes-based regulation (e.g., Schmulow 2020). Seemingly straightforward

\footnotetext{
${ }^{4}$ Most regulatory studies targeting finance are focused on prudential oversight.
} 
constructs like financial health and trust prove difficult to measure in normatively actionable ways, highlighting the need for more theoretical and empirical work on outcome measurement.

Two other important issues that we mostly ignore, are the family of issues around data security, privacy and property rights (Barth and de Jong 2017; Waldman 2018) and malfunctioning financial advice markets (D'Acunto and Rossi 2021; Gomes, Haliassos, and Ramadorai forthcoming).

\section{High and Hidden Prices}

\section{A. Defining the Problem: Regulator perspective}

Regulators often cite high and hidden prices as a key challenge in consumer financial markets. Yet diagnosing high and hidden prices is difficult. For example, regulators often point to complex product menus and contracts as a sign that providers are extracting excess revenue from confused, inattentive, or over-optimistic consumers (Greenwood and Scharfstein 2013). In classical economic models, however, rich menus are viewed as a healthy sign of tailoring products to heterogeneous consumer demand.

Another diagnostic approach focuses on non-compliance with existing regulations like the disclosure mandates discussed below. This approach is conceptually limited in focusing on processes rather than the desired outcomes, and practically limited by resource and legal constraints.

A promising diagnostic development is increased reliance on audits using mystery shoppers, often conducted in partnership with academic researchers. Professional auditors or regular consumers are hired to visit several providers to inquire as clients. These studies show that provider staff maximize commissions and fees rather than making recommendations in the customer's best interest. For example, Giné and Mazer (2021) finds that FSP staff selling various products in Ghana, Mexico and Peru provided little information about financial products voluntarily but disclosed information truthfully when asked. Less than a third of the total cost of products was disclosed voluntarily, and the amount disclosed was uncorrelated with the total cost of the product. Auditors were always offered more expensive products and almost never offered a no-cost account that met their needs (see also Mowl and Boudot 2015). Anagol et al (2017) finds that insurance agents steered purchasers towards unsuitable, strictly dominated products that provided agents with high commission revenues. Audits can thus be used to detect consumer protection problems and to gauge regulatory compliance of FSPs.

\section{B. Defining the Problem: Academic theory and empirical evidence}

Besides the audit studies describe above, another indication that consumers may be overpaying is price dispersion: observably identical individuals paying very different prices for the same product (Giné and Mazer 2021; Karlan and Zinman 2018). Although part of the observed price dispersion may be due to discrimination (see Section 5), most papers in this literature emphasize the importance of search costs and heterogeneity in consumer shopping behavior.

Search frictions can generate rents for providers via market power (Allen, Clark, and Houde 2018; Galenianos and Gavazza 2019). Agarwal et al.(2020) emphasize an important wrinkle for credit (and insurance) markets that is introduced by screening: the possibility of application rejection increases the borrower's effective search costs and can generate adverse selection, even if riskier borrowers do not have higher willingness to pay for credit, producing a positive correlation between search and price paid. Conversely, consumers with high approval probability have the traditional negative correlation.

An alternative set of explanations for high prices emphasizes strategic price obfuscation that preys on consumer confusion, inattention, and/or over-optimism about avoiding contingent fees for paying late, overages, etc. (See Grubb (2015) for a review). A key prediction of Gabaix et al. (2016) is that an increase in the number of competitors may not lower prices towards marginal costs, suggesting that increasing competition will not necessarily improve outcomes if consumers have decision failures. 
Another key prediction of these models is that consumers will be (relatively) insensitive to shrouded prices. Alan et al. (2018) finds evidence consistent with this in a field experiment with a large bank in Turkey. SMS messages promoting a discount on overdraft fees decreased overdraft usage - which violates the classical law of demand - suggesting that consumers were unaware of or underestimated overdraft fees. However, messages that mentioned overdraft availability without highlighting the price increased demand. Neither message campaign caused long-run differences in overdraft usage, providing further evidence for limited memory and attention that could hinder consumers from experiential learning.

Other key predictions of these models are that advertising will be more persuasive than informative and that firms lack incentives to "debias" customers (Gabaix and Laibson 2006). Hastings et al. (2017) explores the nature of advertising of Mexican pension plans by developing a model where workers respond to prices and brand preferences when choosing their plans. The model can account for two stylized facts: workers are not price sensitive as they do not choose the plan that minimized management costs, and firms that invested heavily in advertising have both high prices and large market shares, suggesting that competition on advertising and nonprice attributes substituted for competition on price.

\section{Interventions and evidence on their effectiveness}

\section{Price ceilings and bans}

Interest rate caps are as old as written history (Temin and Voth 2008). At present, more than 70 countries worldwide have interest rate caps (see Maimbo and Gallegos 2014; and for a review, Ferrari, Masetti, and Ren 2018). Most caps are defined in terms of an annual percentage rate (APR), which includes all fees and charges. But other times the cap only applies to the interest rate, thus encouraging lenders to increase non-interest income via fees and commissions. And yet other times a cap applies to only a (typically politically) selected subset of similar products.

Critics of caps argue that lenders are not earning excess profits, and instead caps reduce credit access and quantities. Regulators may view reducing access and/or quantities as desirable (see Section 2), or may view lower prices for some as important enough to accept reduced access for others.

Case studies analyzed in Ferrari et al (2018) suggest that interest rate caps reduced credit availability, increased costs for low-income borrowers, and reduced financial product transparency and diversity. We highlight three examples. In West African countries, the imposition of interest rate caps on microfinance loans has been associated with microfinance institutions withdrawing lending to the poorest borrowers and to remote areas. In South Africa, several financial institutions seem to have evaded the interest rate caps by charging credit life insurance and other service fees, reducing the transparency of the total cost of credit. Lastly, in Japan, the supply of formal credit has contracted and that of informal credit has increased since the imposition of a cap.

In richer-country markets, several natural experiments find reductions in credit supply from caps (e.g., Fekrazad 2020). An important LMIC study is Cuesta and Sepúlveda (2019), which finds that lowering caps in Chile reduced both prices and credit supply, and consequently (with a model of classically rational consumers), estimates reduced consumer welfare on average with larger losses for riskier borrowers. In the United States, Allcott et al (2021) finds that caps harm behaviorally-biased consumers as well.

Interestingly, behavioral industrial organization theory shares the same concerns as classical theory about price caps on base prices. Armstrong et al. (2009), for example, shows that a base price cap can reduce consumer search, dampening price competition for consumers. In contrast, behavioral industrial organization theory reviewed in Heidhues and Koszegi (2018) is far more bullish on capping or prohibiting contingent or add-on prices: "The same case as for safety regulations can be made: if a contract feature is likely to induce many mistakes and has little economic purpose, then banning it is welfare-increasing." We know of examples of such bans - for example on prepayment penalties and on 
upfront fees for debt workout assistance that is contingent on the consumer making a stream of additional payments - but not of any empirical evidence of their effects on consumers, providers, or the market.

\section{Disclosure mandates and prohibitions on deception}

Disclosure mandates are also common, based on the rationale that they will reduce consumer search costs and/or confusion, and promote competition. An influential example is the U.S. Truth in Lending Act of 1968 (TILA), which requires standardized disclosures including the calculation of interest and upfront fees as an APR.

Theory and empirics both point to the limitations of traditional disclosures. Regulations may not cover all key costs, especially those that depend on consumer usage (such as late fees, line of credit draws, and rollovers). Point-of-sale provision may happen too late in the consumer search and decision process (BenShahar and Schneider 2011; Loewenstein, Sunstein, and Golman 2014). Strategic responses by providers - in disclosure form design, for example, or in pricing and sales tactics — can undo regulations' intended effects (Duarte and Hastings 2012; Anagol and Kim 2012), particularly when there is limited and selective enforcement (Stango and Zinman 2011).

Even well-designed and implemented disclosures may not have their intended effects, particularly if consumers have limited attention, other decision limitations like narrow bracketing, and/or face high (perceived) search or switch costs. A randomized evaluation in Mexico that used a sample of borrowers already carrying large credit card balances tested several TILA-like disclosures alongside messages comparing the debt levels and riskiness of cardholders relative to their peers, and finds limited and temporary effects on balances, defaults or account closings (Seira, Elizondo, and Laguna-Müggenburg 2017). Similarly, a randomized evaluation with UK savings accounts finds little effect from behaviorally informed disclosures (P. D. Adams et al. 2019).

There is some evidence, however, that redesigning disclosures with consumer decision failures in mind can improve outcomes, or at least change decisions. Bertrand and Morse (2011) tests new approaches to summarizing payday loan costs and find effects on consumer behavior (which we discuss in more detail in Section 2). Giné et al. (2017) finds that providing a simplified fact sheet to low-income consumers from peri-urban Mexico and Peru in a lab-like setting induces greater price-sensitivity, suggesting that improved consumer understanding could lead to more price competition.

Recently many countries have instituted broad prohibitions on deceptive advertising (World Bank Group 2017) but we are not aware of any compelling evidence on their effects.

\section{Open questions}

There is relatively strong evidence that providers succeed in charging high or hidden prices by exploiting decision failures. The key open questions therefore revolve around prevention.

Starting with traditional levers, one key open set of questions is whether interventions that seek to promote competition actually do so, and whether success in increasing competition leads to better outcomes. Another is whether anything can be done to salvage traditional approaches to product-specific disclosure; the empirical evidence thus far is not particularly encouraging, but disclosure variations are relatively easy to test and it may therefore be worth continuing to develop innovations in content, timing, medium, and source. A third, and particularly challenging, set of key questions to address empirically is the effects of capping or banning prices on secondary, add-on, or contingent features of financial services. A relatively promising avenue here is for theory to generate clearer guidance on the specific market and consumer decision-making conditions under which caps or bans are likely to improve welfare, and for empiricists to set about measuring those conditions. 
A less traditional, but promising, approach to pricing problems is to educate consumers about shrouded fees. Even if some FSPs lack incentives to educate or debias consumers, other FSPs (such as personal financial management apps), NGOs, and government agencies may have incentives more aligned with consumers. We discuss some closely related challenges and opportunities in Section 4.

Another less traditional approach that is gaining traction with regulators is price comparison tools. Market provision has not necessarily improved outcomes (Ellison and Ellison 2009), leading some regulators to consider public moderation of an FSP shopping platform. Of course, FSPs could still respond strategically to mute or undo intended effects, so it will be important to identify how both providers and consumers respond to shopping and search interventions.

\section{Overindebtedness}

\section{A. Defining the problem: Regulator perspective}

As noted at the outset, many LMIC consumers are borrowing for the first time from formal financial institutions and many existing borrowers are taking on more debt. This growth includes both "downmarket" expansions of now-traditional products like mortgages and credit cards and the increased availability of seemingly newer "digital" products that are sometimes linked to payment platforms.

With such growth comes concerns about "overindebtedness"- about consumers taking on more debt than they should reasonably expect to pay back without incurring undue hardship.

One common approach that regulators use to diagnose overindebtedness is to define it "directly", using, for example, a debt-to-income (DTI) ratio cutoff. Conceptually, drawing the line is difficult: How high is too high for DTI? This is especially thorny given theory and evidence suggesting that those willing to take on large debt burdens are often facing a stark need. Overindebtedness may be merely a symptom of a deeper problem, not a cause, and DTI cutoffs may restrict access for those who benefit the most from it, at least in the short run. Practically, even if one knew the magic threshold - and we assert this is not the case - there are definitional and measurement issues in implementing DTI cutoffs. For example, focusing on the DTI numerator, what counts as "debt"? All recurring and outstanding obligations, including utility and rent payments, or just those considered "loans" in a formal sense? All loans, or just those that report to credit bureaus? Further complicating any such rule, some LMICs lack credit bureaus entirely, while bureaus in richer countries still have substantial gaps in coverage for the types of "alternative" products used most intensively by lower-income consumers.

Another common approach is to diagnose overindebtedness based on symptomology, which involves noting an outcome in observational data and inferring that its proximate cause is overindebtedness. Default is a prominent example. Regulators sometimes look at more or less the same symptoms (e.g., high default rates) and make very different diagnoses (e.g., efficient risk-based pricing that serves highrisk borrowers or overindebtedness). Sometimes they look at very different symptoms (e.g., both low and high default rates) and make more or less the same diagnosis (e.g., of overindebtedness). Low default rates are potentially indicative of a debt trap in which borrowers keep refinancing instead of defaulting (Karlan, Mullainathan, and Roth 2019; Skiba and Tobacman 2018). High default rates are potentially indicative of overindebtness based on the deceptively simple intuition: "How can the transaction be good for the consumer, if the lender does not expect to get repaid per the original amortization schedule?" However, this intuition ignores canonical insights from finance: Flexibility has value for the borrower and shifts risk from the borrower to the lender, benefiting the borrower in most cases. Indeed, the microcredit movement has an odd relationship with default as a metric of success; while it is heralded for high repayment rates (often at or near 100 percent), at such high repayment rates lenders are unlikely diversifying risk across borrowers, and thus high-risk, high-return projects are likely going unfunded. 
Some default is a sign of a healthy market. All told, regulators are likely to go astray if they try to diagnose overindebtedness from default rates.

Conflicting diagnoses also arise from observing that consumers want to borrow more and do so when given the opportunity. Empirical evidence abounds that liquidity constraints are binding, thus leading many regulators to infer that market failures like asymmetric information lead to people being underindebted, which then renders people unable to make potentially profitable investments, smooth consumption, or buy desired durable goods. Indeed, the microcredit movement is predicated on this inference. However, extrapolating from this inference to promoting credit access requires the additional assumption that consumers make borrowing decisions in their own best interest. As we discuss next, that assumption pushes against the core concern of consumer financial protection policy.

\section{B. Defining the Problem: Academic theory and empirical evidence}

How do academics diagnose overindebtedness, or lack thereof? Absent a clear normative definition, academics focus on diagnosing the consumer decision failures and market failures that can cause overindebtedness.

\section{i. Theories and evidence of consumer decision failures}

Several types of decision failures can, in theory, generate overborrowing and undersaving (Agarwal, Chomsisengphet, and Lim 2017; Beshears et al. 2018): present bias, exponential growth bias, and inattention to shrouded and complex prices (see also Section 1). Many other commonly cited decision failures, including loss aversion, overconfidence, lack of financial literacy, and scarcity, have underdeveloped or unclear theoretical predictions on overborrowing. For example, a lack of financial literacy could lead a consumer to take on too much debt, or too little debt. A key question about decision limitations is the extent to which consumer meta-awareness dampens any harmful tendencies (in this case toward overindebtedness); not enough is known about this, empirically.

In part because of the difficulty attributing behaviors to specific decision failures (Kremer, Rao, and Schilbach 2019), empirical tests of links between specific decision failures and overindebtedness in LMICs is scant. Two pertinent findings, however: (1) In, Afghanistan, a lesser-known behavioral bias, preference for certainty, is correlated with less loan delinquency (Callen et al. 2014); (2) In India and the Philippines, paying off the debt of individuals who borrowed repeatedly from moneylenders did not lead to reduced levels of debt a year later, and no particular proxy for a decision failure, nor a financial education intervention, mediated the likelihood that the borrower returned to moneylender debt (Karlan, Mullainathan, and Roth 2019).

Casting the net more broadly to include evidence from richer countries, Lusardi and co-authors find that lower financial literacy is correlated with more use of high-cost credit (Lusardi and Scheresberg 2013) and self-assessed overindebtedness (Lusardi and Tufano 2015). Stango and Zinman (2009) finds that exponential growth bias is correlated with greater use of certain types of debt, in patterns predicted by theory. Carvalho et al. (2020) shows that lower "decision-making ability" (DMA), as measured by exhibiting coherent preferences and avoidance of dominated choices in stylized tasks, is correlated with more use of high-cost credit in Iceland. ${ }^{5}$ Meier and Sprenger (2010) finds that present-focused money discounting is correlated with more credit card debt. Allcott et al. (2021) finds that payday borrowers are substantially present focused but, on average, have a high degree of sophistication about their present focus. However, other results in that paper, and others (e.g., Acland and Levy 2015), suggest that learning about one's limitations may be highly context- and product-specific, implying that regulators should not

\footnotetext{
${ }^{5}$ One might hypothesize that low financial literacy and low DMA are related, since they might both measure tendencies to make (financial) mistakes, but the results in Stango and Zinman (2020b) suggest otherwise.
} 
assume that consumer experience will not readily extrapolate to new market conditions or other product markets. ${ }^{6}$

Notably absent from this limited body of work linking decision failures to borrowing decisions is any field evidence that scarcity or related phenomena negatively affects the quality of borrowing decisions (although see Burke et al. (2020) for some circumstantial evidence). It also bears emphasizing that scarcity could in theory lead to better decision-making about debt, if liquidity is the key margin of scarcity and hyper-focus. Also absent is any evidence linking loss aversion to potentially problematic borrowing decisions; if anything, circumstantial evidence points in the opposite direction. ${ }^{7}$

ii. Theory and evidence on market failures that produce oversupply of credit

Why might lenders oversupply credit to consumers? Although many of the most canonical market (and regulatory) failures predict undersupply, certain market failures can lead to oversupply (see Zinman (2014) for a more comprehensive review). Some relate to profiting from consumer decision-making limitations, as discussed above in Section 1. Another, that more directly impacts credit quantities, is a negative repayment externality where a loan from Lender A increases the likelihood the borrower defaults on a (already outstanding) loan from Lender B. The one empirical paper we know of on this important question finds large positive externalities for high-credit-score borrowers, and large negative externalities for low-score borrowers, in the Mexican credit card market (De Giorgi, Drenik, and Seira 2020).

\section{iii. Circumstantial evidence on decision and market failures, and its limitations}

A small body of empirical evidence identifies plausibly causal downstream effects of increased access to consumer credit on proxies for consumer welfare, such as financial condition and subjective well-being. Focusing on LMICs, Karlan and Zinman (2010) finds that access to high-cost installment loans in South Africa improves a range of downstream outcomes but increases stress. ${ }^{8}$ We are not aware of any randomized evaluations on the effects of digital credit, although a number are in progress. A regression discontinuity evaluation of a digital credit expansion in Kenya finds improved consumer financial resilience (Bharadwaj, Jack, and Suri 2019). The randomized evaluations of traditional microcredit find positive effects on a right tail but typically null average effects and, importantly for the overindebtedness issue, no presence of a fat left tail (Banerjee, Karlan, and Zinman 2015; Meager 2019; 2020).

Although encouraging, the evidence that more consumer credit access leads to better consumer outcomes does not actually produce clear policy prescriptions, due to four often overlooked yet important limitations. First, even if we were to take the findings at face value, the question would remain: How much should access be expanded? For example, there may well be non-linearities, such as an inverted Ushaped relationship between access and consumer welfare. Second, and again taking results at face value, improved consumer welfare from one form of credit does not imply that the optimal policy response is to expand access to credit. Even consumers subject to decision failures might benefit from expanded access to one form of credit (e.g., formal consumer loans) by switching away from more expensive forms of credit (e.g., moneylenders). If this channel is driving the results, the best policy option may be to restrict access to all forms of credit, although that requires un-siloed rules and enforcement capacity. Third, the affected consumers in these studies might differ from those affected by new policy restrictions - in the

\footnotetext{
${ }^{6}$ See also Stango and Zinman's (2020a) findings that behavioral biases tend to be stable within-person over time.

${ }^{7}$ Chapman et al. (2019) and Stango and Zinman (2020b) find evidence that loss aversion is positively correlated with cognitive skills, in contrast to most other behavioral biases, in representative U.S. samples.

${ }^{8}$ A small related literature uses randomized evaluations to examine the effects of expanding credit access on the take-up of policy-favored durables and related downstream impacts; see e.g., Tarozzi et al. (2014) on bed nets and Berkouwer and Dean (2020) on energy-efficient cookstoves.
} 
studies cited here, for example, many of the marginal consumers are getting new access, whereas with new policy restrictions many of the marginal consumers would be existing borrowers who lose access. Fourth, no generally accepted summary statistic measure exists for consumer (financial) well-being, raising the question whether this literature is measuring (all of) the right downstream outcomes. This is a particularly important issue if there are tradeoffs, with some consumer welfare proxies improving with expanded access and others declining.

A second body of evidence examines the effects of restricting, rather than expanding, credit access. Breza and Kinnan (2020) is of particular importance, and finds strong evidence of negative general equilibrium consequences from industry-wide shutdowns of microcredit in Andhra Pradesh. Other work on restrictions of credit has focused on payday loans in richer countries and found mixed results (see, e.g., Allcott et al. (2021) for a recent review).

A third body of evidence examines the effects of debtor protection policies such as bankruptcy on borrowers. ${ }^{9}$ This literature has focused on quasi-experimental studies of richer countries and finds large positive effects on outcomes like earnings, foreclosure, and mortality, most strikingly in Dobbie and Song's (2015) U.S. study. ${ }^{10}$ But evidence that debt reduction helps distressed borrowers on the "back end" (ex-post, in academic parlance) does not imply that policymakers should restrict credit access. Instead, consumers may be making sound upfront decisions, experiencing bad luck, and then benefitting from the insurance that debtor protections, including limited liability, are designed to provide. Filing for bankruptcy, or otherwise defaulting, is no more clearly a bad outcome for the consumer than filing an insurance claim.

A fourth piece of field experimental evidence documents the powerful effects of persuasive advertising on high-interest loans in South Africa (Bertrand et al. 2010). Such effects are difficult to square with classically rational demand for debt, particularly given that the study's sample had previous experience with the advertised product and advertising lender.

Perhaps the most compelling circumstantial evidence comes from bringing observational data to quantitative structural models of expensive borrowing. Laibson and co-authors find that a model with substantial present focus and complete naivete thereof can reproduce key empirical regularities of U.S. household balance sheets, including high levels of credit card debt, while classical time-consistent discounting cannot (Laibson, Repetto, and Tobacman 2020; Laibson, Maxted, and Moll 2020). ${ }^{11}$ Having said that, the complete naivete required for this inference is a strong assumption; evidence suggests that consumers learn, at least about specific products, when experience produces clear, repeated and consistent feedback (e.g., Allcott et al. 2021). This makes one wonder whether other decision failures besides present-focus drive decisions around (over-)borrowing.

\section{Interventions and evidence on their effectiveness}

We review common and newer policy and programmatic approaches that focus on preventing overborrowing. ${ }^{12}$ First, price and loan size caps, which seek to reduce the quantity of credit supplied, are

\footnotetext{
${ }^{9}$ Some countries also have legally-sanctioned, industry-coordinated debt consolidation and restructuring programs, like consumer credit counseling services in the U.S. (see, e.g., Dobbie and Song 2020).

${ }^{10}$ There is a related literature, again focused on the quasi-experimental studies of richer countries, on the effects of debt overhang on consumer outcomes. See, e.g., DiMaggio et al. (2020) for a recent review.

${ }^{11}$ See Kremer et al. (2019) and Beshears et al (2018) for discussions of related puzzles around household consumption dynamics and balance sheets that reach a similarly speculative conclusion on the likely importance of consumer decision-making limitations.

${ }^{12}$ See Section 1.C for interventions focused on lowering borrowing costs, and Section 2.B-iii for a brief review of debt forgiveness interventions.
} 
common but have not been evaluated with randomized evaluations. Nor have restrictions on DTI or repeat borrowing, although Allcott et al.'s (2021) simulations suggest that the latter are more likely to benefit present-focused borrowers than price or loan size caps.

Turning to regulations and programs that provide information and/or nudges, Seira et al. (2017) tests traditional disclosures, and debiasing and social comparison nudges, on a large sample of credit card borrowers in Mexico, and finds little evidence of effects on behavior. Adams et al (2018) shows that a nudge away from making minimum credit card payments in the U.K. affects behavior but not outcomes; payment amounts to the nudging lender increase, but overall repayments and other outcomes do not change substantially. Similarly, Bertrand and Morse (2011) shows that providing innovative disclosures to first-time borrowers, in the form of information about costs of product usage and the likelihood of repeat borrowing, reduces borrowing from the nudging lender. ${ }^{13}$

Financial education interventions provide some combination of actionable information, basic principles, and advice. Kaiser et al.'s (2020) meta-analysis finds that such interventions have modest average effects (0.056 standard deviations) on various borrowing behaviors across 17 randomized evaluations from LMICs. We are unaware, however, of findings with a strict focus on overindebtedness.

\section{Open questions}

We view research on diagnosing and treating overindebtedness to be wide open, and briefly summarize our views on which questions merit particular focus.

One is outcome measurement. In principle, it is possible to directly measure overindebtedness, and researchers would do well to take methodological guidance from the painstaking efforts of Benjamin, Heffetz, Kimball and co-authors (e.g., 2020) to improve the measurement and interpretation of subjective well-being. In the meantime, useful starting points are the questions developed by Lusardi and Tufano (2015), and the CFPB's Financial Well-Being battery (CFPB 2017). The importance of this work is heightened by increasing interest in consumer outcomes-based regulation (e.g., Schmulow 2020).

A second line of inquiry is linking specific decision failures to borrowing decisions. One key set of questions revolves around the extent to which consumers learn to make better decisions and develop meta-awareness of their limitations. A related question is how various decision failures interact to affect consumer welfare and its implications for policy. ${ }^{14}$

A third line of inquiry is how competition affects debt burdens in equilibrium. Does competition for biased consumers make matters worse, as predicted by some behavioral industrial organization theories (Heidhues and Köszegi 2018)? How does increased competition affect repayment externalities and lenders' incentives to meet any consumer demand for overborrowing?

A fourth line of inquiry is unpacking the (mal-)functioning of advice markets, whether they presently cure any decision failures, and how they might be redesigned or regulated to produce better outcomes. Most

\footnotetext{
${ }^{13}$ Donnelly et al. (2020) finds that a product feature giving consumers the option to allocate repayments to particular purchases, tested with a large credit card issuer in Australia as a novelty but widely available in many other countries, increases repayments to that issuer. However, results using only the random variation engineered by the experiment are imprecise.

${ }^{14}$ One proposed approach is to presume that any consumer decision failures have reinforcing effects on outcomes (for example, all pushing toward overindebtedness) and use a "reduced form sufficient statistics" approach to welfare and policy analysis (e.g., Chetty (2015)). But this assumption has not been well-validated empirically and these models are only beginning to accommodate the cross-consumer heterogeneity that we suspect is important empirically (e.g., Allcott, Lockwood, and Taubinsky 2019). Another approach theorizes that limited attention is a foundational bias that produces many others (e.g., Gabaix 2019); this is important to test as it implies that treating attention could cure many presumed decision-making ills.
} 
research and practice has focused on the asset side of household balance sheet, but, as Zinman (2015) argues, debt is where the money is for low and moderate income consumers.

A fifth line of inquiry is measuring the extent to which pro-savings interventions affect debt burdens and overall financial condition. Nudging or shoving consumers who are borrowing expensively to start saving at relatively low rates of return, as many microfinance institutions and "asset-building" programs do, is a dubious strategy in the absence of empirical evidence that such interventions produce very powerful savings habits.

Finally, although we hesitate to recommend policy experimentation without a firmer empirical evidence base on the extent and nature of overindebtedness problems, we do concede that it could be fruitful to test innovative approaches suggested by theory. Examples include waiting periods, ${ }^{15}$ consumer licensing, and restrictions on repeat borrowing.

\section{Post-contract Exploitation}

\section{A. Defining the Problem: Regulator perspective}

In addition to the set of "upfront" pricing problems that arise during the marketing of financial services addressed in Section 1, various "post-contract" problems can arise after consumers take-up services. Such practices may be costly to individual consumers and create broader societal costs by reducing trust in financial institutions.

One set of problems, charging extra fees and markups, has been linked to FSPs outsourcing marketing and delivery to agents. Agent networks have helped FSPs grow rapidly by economizing on fixed costs, but regulators are concerned that this business model creates incentive problems (Agent Network Accelerator 2016). For example, there is evidence that agents deviate from FSP pricing policy by taking side payments or simply ignoring it (Davidson and Leishman 2012; EFInA 2018). ${ }^{16}$ Also concerning is evidence that extra agent fees are disproportionately paid by less empowered customers, including women, low-literacy citizens, and individuals living in remote areas (Brown et al. 2019; Annan 2020a). Of course, agent pricing practices could (partly) reflect pro-competitive pressures rather than rent extraction or unintended consequences of competition. There is evidence of tight agent profit margins, and self-reports indicating lack of commercial viability if limited to the official tariff structure (e.g., Brown et al. 2019).

Service add-ons without clear customer consent also seem prevalent, although empirical evidence on this comes mostly from a relatively small set of regulator enforcement actions. Anecdotally, some add-ons are imposed through opt-out defaults that exploit disclosure and consumer decision limitations discussed above. Others practices are more blatant. India's Bharti Airtel, for example, was sanctioned by regulators for opening Airtel Payments Bank accounts without customer consent and linking those accounts to customers' national digital ID so that — unbeknownst to the customer-public subsidy payments would flow to the accounts by default (M. Singh 2017).

Abusive debt collection practices also seem prevalent. Prohibited or discouraged practices include attempts to collect debts that have been repaid or forgiven, dunning, public shaming, threats, contacting

\footnotetext{
${ }^{15}$ Burlando et al.'s (2020) regression discontinuity evidence from Mexico, which finds that doubling digital credit disbursement time from ten to twenty hours substantially reduces default rates, provides some empirical motivation for experimenting with waiting periods.

${ }^{16}$ Note that this charging of extra fees by the agent also relates to the theme of price shrouding mentioned above, but differs slightly in that it often violates company or regulatory policy on tariffs and, therefore, would not have been disclosed at the time of registration.
} 
family members or co-workers, house visits, and failing to disclose delegation to a third-party collector. Such practices have attracted global attention to Kenya's digital credit market, and the continued prevalence of enforcement actions in richer countries suggests that their long-standing protections have not fully deterred prohibited conduct.

\section{B. Defining the Problem: Academic theory and empirical evidence}

We characterize these post-contract problems as reflecting supply-side moral hazard, by which we mean that problems arise because the provider does not adhere to the terms of the contract or the law with regards to how they charge fees, register clients for services, or collect on loans. ${ }^{17}$ Such problems can arise from imperfect contracting between customers and firms, and more specifically may reflect the market power of individual firms, principal-agent problems related to corporate governance, externalities, and/or limited accountability arising from weak regulatory and legal institutions. ${ }^{18}$ Academic work identifying the extent and causes of supply-side moral hazard in consumer financial services is limited. One key question is the extent to which such problems dissipate as a market matures. An experiment with garment workers in urban Bangladesh finds some encouraging evidence on this score through a consumer learning channel: Workers with digitized wage payments were more likely to personally execute transfers through their own phones, avoiding mobile money agents and extra fees. There is also suggestive evidence that this produced a positive market externality by making agents less likely to overcharge inexperienced customers (Breza, Kanz, and Klapper 2020).

A related issue that is also important in theory but largely unexplored empirically is whether increased competition reduces undesirable outcomes like post-contract exploitation. We discuss the potential impact of consumer decision failures and repayment externalities in other sections, and focus here on other externalities. Network externalities are potentially important in payments and other platform markets, and can lead to consolidation (e.g., Crouzet, Gupta, and Mezzanotti 2020). However, the literature on "contestability" versus competition demonstrates that market concentration in network industries does not necessarily imply poor consumer experience, as even monopoly providers must compete to forestall entry threats (e.g., Tirole and Rendall 2017). Nevertheless, concerns remain about anti-competitive behavior in digital economies. For example, mobile money competitors have been blocked from accessing USSD channels and digital credit lenders have failed to comply with credit information sharing systems. ${ }^{19}$ In addition to network externalities, trust externalities can lead to firms over-investing in extracting surplus from consumers and under-investing in mechanisms for redressing customer complaints.

\section{Interventions and evidence on their effectiveness}

Complaints channels and Market Monitoring: Technological progress in the digitization of complaints channels, widespread use of mobile phones, and increasingly accessible high-powered analytical solutions, such as machine learning, may improve the ability of regulators to monitor consumer problems and improve enforcement. Specifically, new mechanisms for surfacing customer complaints are increasingly touted as solving customer problems, helping firms identify areas of improvement, assisting regulators in market monitoring, and discouraging malfeasance in the first place. However, there is evidence that financial customers in LMICs use formal complaints channels infrequently (e.g., Kantar InterMedia 2016), and that LMIC regulators are far less likely than high-income country counterparts to

\footnotetext{
${ }^{17}$ We note that there may be cases where an agent of the institution does not violate the terms of the contract per se, but does manipulatively guide the client to an option or service that is clearly not in their best interest.

${ }^{18}$ Extra fees charged by agents could also theoretically be explained by high switching costs and models with limited consumer comparison as covered in the previous section.

${ }^{19}$ USSD (Unstructured Supplementary Service Data) is a protocol used to send text messages commonly used among LMIC mobile money providers.
} 
mandate that FSPs handle complaints, report complaints to the government, or inform customers of dispute resolution mechanisms (World Bank 2017). Technologies such as social media and chatbots can democratize access for communicating complaints and can streamline the process of FSPs responding with support services. Mazer and Onchieku (2019) identify and prioritize consumer concerns with financial services through the \#KOT Kenyans on Twitter community, and Tully \& Madrid Morales (2020) demonstrate the broad use of social media by consumers to communicate complaints. Bird, Longman, and Mazer (2020) shows how customer services complaints data from MNOs related to DFS in Uganda provide a rich source of information for diagnosing consumer protection issues.

Dispute Resolution: For minor post-contracting issues, customer support or self-service FAQs may suffice. For example, the RegTech for Regulators Accelerator worked with the Central Bank of the Philippines to build a customer complaint chatbot to process customer complaints and found evidence that it led to faster responses (di Castri, Grasser, and Kulenkampff 2019), although evidence of effects on outcomes is lacking.

Resolution of larger disputes may require broader development of the legal system. There is some promising evidence on the impacts of improved legal representation for poor LMIC citizens. In an RCT in Kenya, Aberra and Chemin (2021) finds that free legal representation increased the security of property rights, which translated into greater credit access and agricultural production. Similarly, Sadka et al.'s (2018) randomized evaluation in Mexico City's labor courts finds that information about potential outcomes and conciliation services improves settlements for workers, but only if the plaintiff is present, suggesting attorneys do not share this information with their clients. Mandated arbitration is a prevalent alternative resolution system that tends to be viewed dimly by consumer advocates, at least in part because it is viewed as a shrouded attribute (e.g., Ben-Shahar 2016).

Increasing Competition: Busso and Galiani (2014) randomizes entry of existing small neighborhood convenience stores into the network of retailers certified to accept welfare food vouchers in the Dominican Republic, and finds quality increases and price drops, with larger price drops in areas with more entrants. Such retailers closely fit the profile of mobile money retail agents in many countries and serve the poorer population segments that are often the target of extra fees.

Facilitating consumer learning and agent self-regulation: An experiment among mobile money customers and agents in Ghana finds that informing consumers about the official fees for common local transactions not only improved the experience of the treated customers, but also led agents to reduce their own misconduct (Annan 2020b). Taken together with Breza et al. (2020), where consumer learning happened organically as the result of introducing a new product, this suggests that informational interventions hold promise to improve consumer and market outcomes.

Debt collection harassment: Breza and Kinnan (2020) examines the impacts of an emergency ordinance that drastically reduced the ability of microfinance lenders to collect on loans, ostensibly to curb abusive lending and collection practices at the height of what is referred to as the Andhra Pradesh microfinance crisis (Cole and Saleman 2015). The policy was followed by almost universal default in the state of Andrea Pradesh, which the authors find caused subsequent reductions in credit supply throughout India. The reduced access to credit led to significant decreases in household wage earnings and consumption. Interventions specifically targeted at collection practices might perform better, of course.

\section{Open Questions}

Among post-contract exploitation topics, we identify three broad policy areas for further research: complaint and support systems; service quality and fees of agents; and debt collection practices. 
Technology can transform complaint systems, though the impact of this potential transformation on vulnerable consumers remains understudied. On the one hand, data costs, differential internet access, and language barriers may render digital platforms less accessible. On the other hand, the informality and lower cost of digital (versus in-person) complaints may offer greater visibility on vulnerable consumers. Further investigation on the selection of different consumer segments into and out of alternative complaints channels is needed. We also need to learn more about the causal impacts of new complaint systems on provider behavior, dispute resolution, trust in financial institutions, use of financial services, and general consumer welfare. Much could be learned on institutional and operational design of complaint systems. Testing different institutional arrangements for market monitoring - whether through, for example, non-government civil society institutions, appointed ombudspersons, etc.- - may suggest alternatives to standard government regulatory arrangements. If and how there may be a case for public subsidy and/or coordination of the complaint system has important policy implications.

Problems with FSP agent service quality and fees also offer an exciting focus for further research. Alternative approaches to inducing greater retail competition through both government policy and FSP corporate policy, and the impacts of competition on agent business models and consumer experience, are fertile grounds for new work. The effectiveness of technical and behavioral solutions for better informing consumers about mandated fees and service quality are understudied. How to improve the agent experience for women and vulnerable customers also remains an important topic. If and how downward pressure on extra agent fees affects the sustainability of the agent business model remains an important research question, as limitations on incentives to expand the distribution networks can impose social welfare costs by constraining financial inclusion among those still out of reach of formal financial services.

Finally, too little is known about debt collection and how to systematically diagnose harmful practices. Improved complaints and market monitoring approaches may aid in better describing the incidence and extent of harassment. New experimentation, for example with contract design for in-house collection staff and third-party collectors, would aid in guiding regulators and corporate managers while also addressing compelling theoretical questions on incentives and optimal contracting.

\section{Fraud}

\section{A. Defining the Problem: Regulator perspective}

Fraud is amorphous and thus can be challenging to detect, particularly in its early stages. Some frauds operate at the institutional level. This could be a Ponzi scheme in which the entire entity is a fraud, a largescale phishing operation, or internal corruption at a financial institution that puts consumer deposits at risk. Other frauds are perpetrated by individuals faking SMS messages to engender trust and extract money or goods; impersonating a formal financial institution in order to abscond with funds; creating a personal lending app that lures users to pay fees to obtain access to cheap loans, but which offer no actual service; or phishing for passwords or account numbers. There can also be problems with fraudulent agents of legitimate institutions, such as mobile money agents who cheat clients, or bank employees who steal from clients and/or the firm (Buku and Mazer 2017).

There is considerable overlap from a regulator's perspective between these types of fraudulent activities and the post-contracting exploitation issues discussed in Section 3. The difference is severity and intent: 
here we discuss situations where an individual or institution is trying to consummate a transaction fraudulent at its core-likely criminal (rather than deceptive) and certainly manipulative. ${ }^{20}$

\section{B. Defining the Problem: Academic theory and empirical evidence}

Fraud occurs when market and legal forces exacerbate or otherwise fail to counterbalance the greed and corruption that underlies motivations for fraudsters. Consequences of fraud can be examined at two levels: direct effects and indirect market-level effects.

The first-level effect are the direct costs to the consumer from loss of funds and time, and stress. Such direct costs are particularly concerning if vulnerable consumers are the more likely victims of fraud. Over 20 percent of banked respondents in Uganda, Kenya, and Nigeria reported losing money to fraud or scams, or paying illegal extra fees (such as bribes) in the prior six months in Kantar InterMedia's 2016 Financial Inclusion Insights Survey. Two Ponzi schemes in Colombia in 2008 had over half a million customers, with invested funds equal to 1.2 percent of annual GDP (Hofstetter et al. 2018). In Uganda, staff and agents at a mobile money provider pilfered millions of dollars from mobile money accounts (Morawczynski 2015).

With many experiencing direct fraud, it is likely—with face-to-face gossip and social media — that almost everyone knows someone who has been defrauded. This direct effect may therefore cause an indirect negative externality: a general equilibrium market failure where "good" transactions are not consummated because consumers cannot distinguish good from bad actors. This in turn can cause markets to thin or unravel; for example, that consumers who want to save in a financial institution do not, or that those who want to send money via a mobile agent do not. These foregone, mutually beneficial trades imply reduced social welfare (e.g., Sapienza and Zingales 2012).

The available evidence suggests that indirect effects are also prevalent and costly. For example, the Mexico World Values Survey finds that trust in banks is especially low among the poor: 71 percent of those with less than a primary school education report low trust in banks, compared to 55 percent of those who completed primary school, and 46 percent of those who completed university. In addition, 24 percent of a sample of low income households that receive a government cash transfer reported not saving in the bank account that receives the transfer because they did not trust the bank (Bachas et al. 2020). In Kenya, a survey in three rural areas found that 8 percent of people who knew of a particular local bank did not trust it (Dupas et al. 2016). In Uganda and Malawi, in a sample of poor, rural households, 16 percent in Uganda and 5 percent in Malawi report knowing someone who has lost money deposited in a bank and 60 percent in Uganda and 16 percent in Malawi report having little or no trust in banks (Dupas et al. 2018). Similarly, and also in Uganda, only 44 percent of a sample of young adults groups believed savings in a bank would definitely not be stolen (Horn et al. 2020). Experimental evidence on such indirect effects come from the US mortgage market, in which "good" offers were met with suspicion by potential borrowers, implies that borrowers were unable to separate good from untrustworthy mortgage offers (Johnson, Meier, and Toubia 2019).

\footnotetext{
${ }^{20}$ We do not discuss fraud that falls under the purview of prudential regulators (such as willful disregard for liquidity, leverage, or risk management rules), and as such also do not discuss deposit insurance in low-income countries, an important protection for consumers depositing with regulated institutions (Demirgüç-Kunt, Karacaovali, and Laeven 2005).
} 
Social media can be used to quickly and cheaply detect fraud and spread information on dubious entities (see also Section 3 on the rise of market monitoring technology). But social media can be a tool for fraudsters as well, and potentially exacerbate inefficient social learning (Banerjee 1992).

The challenge for regulators strikes us a very similar to that facing media literacy advocates across the world: how to guide people to trust what they should trust, and mistrust what they should mistrust. Recent work in political science suggests that limited attention (as opposed to mere confirmation bias) is a key factor in the spread of fake news and other disinformation (Pennycook and Rand 2020). This finding is encouraging, as it suggests that increasing the profile of accurate sources can shift both trusting and distrusting people towards more accurate beliefs about what to trust and what not to trust.

\section{Interventions and evidence on their effectiveness}

As with the other problems considered in this review, the common approach to combatting fraud has been indirect by promoting competition. We are not aware, however, of any empirical evidence on the impact of competition in mitigating fraud in consumer financial markets.

Interventions that more directly address fraud include institutional oversight such as banking supervision (outside the scope of this review), consumer complaint and redress processes (covered in Section 3), and informing consumers.

Burke et al. (2020) tests short videos and text messages providing information to US consumers about the risk of financial fraud in investments. They find short-term reductions in fraud susceptibility, and some evidence that consumers get better at distinguishing between legitimate and fraudulent offers. Reminders make these effects more persistent. In Peru, a randomized evaluation of a three-hour training session designed specifically to build trust in financial institutions for beneficiaries of a conditional cash transfer program finds a 33 percent increase in trust and a corresponding increase of 1.6 percentage points in the savings rate from the cash transfers (Galiani, Gertler, and Navajas-Ahumada 2020).

Consumers can also learn through direct experiences. In Mexico, for the cash transfer recipients cited above, for example, recipients left small amounts in their accounts after receiving debit cards and repeatedly checked the account balance to ensure that their money was still there. Over two years with the card, the number of account balance checks fell substantially and beneficiaries' probability of reporting a lack of trust in the bank fell by 33 percent (Bachas et al. 2020). Similarly, being given fee-free savings accounts decreased the mistrust of poor, rural households from 60 percent to 50 percent in Uganda but not in Malawi, where the base mistrust rate was an already-low 16 percent (Dupas et al. 2018).

In the Uganda young adult sample mentioned above, we learn about both information campaigns and direct experience, via a four-arm study comparing financial education (which includes components on how to identify trustworthy financial institutions), savings account access, and both (Horn et al. 2020). The education arms produce lasting increases in trust relative to the control group, while the account-only arm does not. But effects on savings and income are similar across all arms, suggesting that increasing measurable trust is not necessarily an essential input for consumer behavior change and outcome improvement.

\section{Open questions}

Evidence on detecting, preventing, and treating fraud, as well as on building a good balance of trust and wariness in consumers, is heavy on anecdotes and light on systematic, rigorous evidence.

For detecting and addressing fraud directly, new Regtech opportunities abound both for new approaches to regulation and for research to test their effectiveness. Regulators with the proper capacity could scrape social media to identify fraud, investigate cases, and then use social media again to warn the public about 
specific cases. More comprehensively, regulators could feed such information to a public report card platform (such as an app or a website) that identifies both bad and good actors. This could also incorporate issues raised in the Post-Contract Exploitation section. Research can draw from computer science to build tools for scraping and analyzing natural language posts in social media, as well as from social science and law to learn how best to promote and evaluate such efforts. Further work, likely from a combination of computer science and accounting, can also develop methods for firms to conduct stronger internal audits of transactions to identify potential agent fraud (West and Bhattacharya 2016).

For educating and persuading consumers, opportunities abound to meet three key programmatic and research challenges head-on. One is measuring trust, and - given that more trust is not always betterdeveloping success metrics for interventions. Another opportunity is learning how to strike a better balance between context-relevance for a given study versus universality for cross-study comparability. Existing measures, such as the World Value Survey questions, ask about overall instinct aiming to capture more of a personality measure, and laboratory experiments such as the trust game have proven questionable for measuring trust (e.g., Schechter 2007). A third opportunity is testing to find the right balance between providing actionable advice ("These are the types of providers you should (mis)trust.") and teaching consumer skills, frameworks, and principles to apply in novel situations. Financial literacy and advice interventions grapple with similar issues, so presumably there are gains from trade between intervention designers in related domains. It also will be critical to test whether and how various factors mediate the effects of content designed to improve trust in trustworthy actors and increase wariness of untrustworthy ones. Potential mediators include content medium, information source, endorsements, and baseline (mis)information environment. Overall, there are likely opportunities to glean from and contribute to the social learning literature (e.g., Chandrasekhar, Larreguy, and Xandri 2020).

\section{Discrimination}

Discriminatory practices towards women, minority groups, and other potentially vulnerable groups rightly concern regulators (e.g., Toronto Centre 2019). We limit this section to a broad overview with pointers to pertinent literatures, given its overlap with the voluminous literature in other fields in economics and law (e.g., see Charles and Guryan 2011; Bertrand and Duflo 2017) as well as gender policy (e.g., see Jayachandran 2015)..

\section{A. Defining the Problem: Regulator perspective}

Pernicious discrimination happens when an FSP treats individuals worse because of their (perhaps misperceived) group affiliation. Examples include discouraging individuals from engaging with the FSP, lowering approval rates, excluding outright, or charging more. Although discriminating based on creditworthiness is accepted practice (risk-based pricing), many countries prohibit the use of "protected characteristics" like race, gender, age, and neighborhood in approval and pricing decisions (Morse and Pence 2020; World Bank 2017). Despite digital finance's relative youth, many FSPs have already been scrutinized and/or sanctioned for discriminating (Annan 2020a; Matiwane 2019).

The most common regulatory approach to defining and detecting discrimination in consumer financial services is not based on pernicious intent—which is often difficult to ascertain, as discussed below-but rather on "disparate impacts". Under this standard, the key question is whether a protected group gets worse outcomes (e.g., loan approval rate or contract terms) after controlling for all other relevant characteristics.

An additional concern for regulators is that that increased reliance on technology may exacerbate inequalities. Access to a mobile phone is usually a prerequisite for using digital financial services and- 
although mobile phone ownership is on the rise globally-women are 6.6 percentage points less likely than men to own a mobile phone (GSMA 2020). The Economist Intelligence Unit's Inclusive Internet Index 2020 finds a 34.5 percentage point gender gap in access to the internet in the least-developed countries. In addition, an ID is a requirement for accessing financial and public services, and 44 percent of women in lower-income countries do not have an ID, compared with 28 percent of men (World Bank 2019). The poor are also less likely to have access to phones, internet, and IDs. At the same time, sharing information like photos and phone numbers online or with agents has risks for women and marginalized populations in some countries including harassment, blackmail, and shaming (Sambasivan et al. 2019).

\section{B. Defining the Problem: Academic theory and empirical evidence}

There are two main models of discrimination in the economics literature. In "taste-based discrimination", decisionmakers dislike marginalized groups. In "statistical discrimination", the differential treatment of members of the discriminated group is due to imperfect information, with decisionmakers making inferences based on group characteristics rather than individual characteristics, thus making discrimination the result of a signal extraction problem. Bohren et al. (2019) argues that often what is called "statistical discrimination" is actually rooted in inaccurate beliefs that are themselves biased against the discriminated group (see also Bordalo et al. 2016 for a model of inaccurate sterotypes). This distinction is quite important when grappling with how to address disparate treatment: if the "profitmaximizing" policy is in fact discriminatory (as with accurate statistical discrimination), this suggests a deeper societal challenge, one that requires regulation, monitoring, and/or perhaps subsidy, to address. If on the other hand firms or their agents forgo profits to discriminate based on inaccurate beliefs or, worseyet, "taste", then more direct punitive regulatory policy may be appropriate.

Discrimination can happen at various stages in the contracting of financial products. First, in the customer acquisition or discouragement stage, through decisions about e.g., physical location, advertising, and customer service. Second, in the contracting stage (see also Sections 1, 2, and 4 above). Third, in the postcontracting stage (see also Sections 3 and 4).

Detecting discrimination in customer acquisition stage is particularly challenging due to a lack of data on those discouraged from engaging with an FSP due to expected or realized discrimination. The two main methods for addressing this challenge are audit studies (discussed in Section 1 and below) and the Becker (1957) "outcome test". The latter estimates whether services extended to a protected group have relatively high marginal profits, controlling for all other relevant characteristics. Higher marginal profits indicate that the FSP is discriminating by not competing for clients in the protected group to the point where contract terms are set per a competitive equilibrium, as e.g., Dobbie et al. (forthcoming) find is the case in U.K. consumer lending.

Algorithmic or machine learning assessment of financial standing has the potential to reduce discrimination in face-to-face assessments, but recent evidence from richer countries finds that these models also can generate differential treatment by race and gender (Fuster et al. 2020). In some cases, algorithms may be fairer than humans as they remove some of the personal bias that comes through in face-to-face interactions. In the US, Bartlett et al. (2019) compares algorithmic and face-to-face lending and finds that face-to-face lenders charge otherwise-equivalent minority borrowers 7.9 basis points higher for mortgage loans, costing $\$ 750$ million annually. Algorithmic lending also discriminates, but by 40 percent less than face-to-face lenders.

Evidence from LMICs is scant. Dvara Research finds that use of artificial intelligence in credit underwriting may disadvantage traditionally vulnerable segments of the population in India (A. Singh and Prasad 2020). Bjorkegren \& Grissen (2018) finds that alternative credit scoring - using information like utility bills, mobile money history, social media and other online behavior, number of contacts, and psychometric evaluations - is expanding credit access to populations that may not have the documentation or collateral traditionally used during the loan approval process. 


\section{Interventions and evidence on their effectiveness}

In 2017, 65 percent of 124 jurisdictions surveyed had laws prohibiting discrimination against certain populations in finance, while only 44 percent of low-income jurisdictions did (World Bank 2017). Such laws can be enforced through regulatory examinations that are part of the supervision process, through audits, or through complaints and the legal system. Countries including South Africa, India, and the United Kingdom cite financial services ombudsmen as helping to combat discrimination in finance (Izaguirre 2020). While these approaches have not been rigorously evaluated in LMICs, Haendler and Heimer (2021) suggests that in the U.S., regulators themselves may discriminate.

Some studies have evaluated debiasing campaigns for FSP staff and have found mixed results at best. For example, Montoya et al (2020) finds that male loan officers in Chile did not reduce their existing levels of discrimination against female loan applicants when presented with evidence that female borrowers have higher loan repayment rates than male borrowers. Nor did loan officers in the Philippines lend more to low-income households when presented with evidence that they are as creditworthy as wealthier borrowers and trained with a scorecard to estimate income quickly. In fact, there is some evidence that the training increased lending to wealthier individuals (Karlan, Osman, and Zinman 2019).

With respect to artificial intelligence and algorithms in fintech, regulation in LMICs to date has focused on data privacy and disclosing to consumers how their personal information will be used, and whether and how it will be shared (World Bank Group 2017). Due to the black box nature of algorithms, and the fact that they evolve, developing frameworks for fairness and some degree of transparency is not straightforward. Researchers have made progress towards frameworks for ethical artificial intelligence and machine learning algorithms, but these have not yet been widely applied, in LMICs. ${ }^{21}$

\section{Open research questions}

This is an open - and high priority - area of research, as much of what we discussed above is speculative. In particular, more research is needed on detecting discrimination in product markets where refusals or discouragement are hard to observe due to lack of data. Using audits that change the customer's identity in terms of gender, race, ethnicity, religious affiliation, etc. will be fruitful. Monitoring regulators for lax enforcement and/or discrimination also will be important. And although anti-discrimination efforts in LMICs often focus on gender, in most countries there are other vulnerable groups that warrant attention as well.

We also need further studies of agent or branch engagements. Are decisions driven solely by profit considerations, or do FSPs try to avoid certain areas that may be profitable but have a high density of oppressed groups? Likewise, to the extent that discrimination is agent-based - such as, for example, in mobile money operations - interventions that aim to shift social norms may also be appropriate, although they are outside the scope of this review.

Regulating black-box algorithmic lending (or other products) to prevent discrimination is an important and growing area, with attention from computer science and legal theory as well as economics. This is clearly a case where solutions should travel across borders, from poorer to wealthier and vice versa.

\section{Conclusion}

We cover five consumer financial protection issues of growing concern to various stakeholders in LMICs: high and hidden prices, overindebtedness, post-contract exploitation, fraud, and discrimination. We

${ }^{21}$ Entry points to this literature include Bartlett et al. (2019), Corbett-Davies and Goel (2018), and Pandey and Caliskan (2020). Li, Raymond and Bergman (2020) argues in the context of labor hiring that algorithms not only exploit past data but take into account the availability of data for certain subgroups could be used to boost diversity. 
highlight many tensions between how regulators and academic diagnose the extent and nature of these problems, with some growing common ground in the use of audit studies and consumer complaint data. We also find that academic evidence tends to cast doubt on the effectiveness of standard policy approaches like mandated disclosure, restricting contract terms (such as interest rate caps), and pricefocused competition policy, although again we find some common ground in restricting add-on pricing practices, improving consumer redress channels, and protecting against discrimination or bias. Open questions far outnumber those answered definitively enough to provide actionable evidence for policy, and for each problem we highlight particularly important lines of inquiry regulators and researchers should pursue collaboratively going forward. 


\section{References}

Aberra, Adam, and Matthieu Chemin. 2021. "Does Legal Representation Increase Investment? Evidence from a Field Experiment in Kenya." Journal of Development Economics 150 (May): 102612.

Acland, Daniel, and Matthew Levy. 2015. "Naivete, Projection Bias, and Habit Formation in Gym Attendance." Management Science 61 (1): 146-60.

Adams, Paul D., Stefan Hunt, Christopher Palmer, and Redis Zaliauskas. 2019. "Testing the Effectiveness of Consumer Financial Disclosure: Experimental Evidence from Savings Accounts." National Bureau of Economic Research Working Paper, NBER Working Papers, , March. https://ideas.repec.org/p/nbr/nberwo/25718.html.

Adams, Paul, Benedict Guttman-Kenney, Lucy Hayes, Stefan Hunt, David Laibson, and Neil Stewart. 2018. "The Semblance of Success in Nudging Consumers to Pay down Credit Card Debt."

Agarwal, Sumit, Souphala Chomsisengphet, and Cheryl Lim. 2017. "What Shapes Consumer Choice and Financial Products? A Review." Annual Review of Financial Economics 9 (1): 127-46.

Agarwal, Sumit, John Grigsby, Ali Hortaçsu, Gregor Matvos, Amit Seru, and Vincent Yao. 2020. "Searching for Approval." w27341. National Bureau of Economic Research.

Agarwal, Sumit, Wenlan Qian, and Ruth Tan. 2020. Household Finance: A Functional Approach. Palgrave Macmillan.

Agent Network Accelerator. 2016. "Successful Agent Networks." Helix Institute of Digital Finance. http://www.helixinstitute.com/sites/default/files/Publications/New\%20Successful\%20Agent\%20Networks\%20\%20Final\%20-\%20Feb.\%202017.pdf.

Alan, Sule, Mehmet Cemalcilar, Dean Karlan, and Jonathan Zinman. 2018. "Unshrouding: Evidence from Bank Overdrafts in Turkey." The Journal of Finance 73 (2): 481-522.

Allcott, Hunt, Joshua Kim, Dmitry Taubinsky, and Jonathan Zinman. 2021. "Are High-Interest Loans Predatory? Theory and Evidence from Payday Lending."

Allcott, Hunt, Benjamin B. Lockwood, and Dmitry Taubinsky. 2019. "Regressive Sin Taxes, with an Application to the Optimal Soda Tax." Quarterly Journal of Economics 134 (3): 1557-1626.

Allen, Jason, Robert Clark, and Jean-François Houde. 2018. "Search Frictions and Market Power in Negotiated-Price Markets.” Journal of Political Economy 127 (4): 1550-98.

Anagol, Santosh, Shawn Cole, and Shayak Sarkar. 2017. "Understanding the Advice of CommissionsMotivated Agents: Evidence from the Indian Life Insurance Market." Review of Economics and Statistics 99 (1): 1-15.

Anagol, Santosh, and Hugh Hoikwang Kim. 2012. "The Impact of Shrouded Fees: Evidence from a Natural Experiment in the Indian Mutual Funds Market." American Economic Review 102 (1): 576-93.

Annan, Francis. 2020a. "Gender and Financial Misconduct: A Field Experiment on Mobile Money." https://papers.ssrn.com/sol3/papers.cfm?abstract id=3534762.

- 2020b. "Misconduct and Reputation under Imperfect Information." Working Paper, September. https://papers.ssrn.com/abstract $=3691376$.

Armstrong, Mark, John Vickers, and Jidong Zhou. 2009. "Consumer Protection and the Incentive to Become Informed.” Journal of the European Economic Association 7 (2-3): 399-410.

Bachas, Pierre, Paul Gertler, Sean Higgins, and Enrique Seira. 2020. "How Debit Cards Enable the Poor to Save More." Journal of Finance forthcoming.

Banerjee, Abhijit. 1992. "A Simple Model of Herd Behavior.” The Quarterly Journal of Economics 107 (3): 797-817.

Banerjee, Abhijit, Dean Karlan, and Jonathan Zinman. 2015. "Six Randomized Evaluations of Microcredit: Introduction and Further Steps." American Economic Journal: Applied Economics 7 (1): $1-21$. 
Barth, Susanne, and Menno D. T. de Jong. 2017. "The Privacy Paradox - Investigating Discrepancies between Expressed Privacy Concerns and Actual Online Behavior - A Systematic Literature Review." Telematics and Informatics 34 (7): 1038-58.

Bartlett, Robert, Adair Morse, Richard Stanton, and Nancy Wallace. 2019. "Consumer-Lending Discrimination in the FinTech Era," Working Paper Series, .

Becker, Gary. 1957. The Economics of Discrimination. Chicago: The University of Chicago Press. https://press.uchicago.edu/ucp/books/book/chicago/E/bo22415931.html.

Benjamin, Dan, Kristen Cooper, Ori Heffetz, and Miles Kimball. 2020. "Self-Reported Wellbeing Indicators Are a Valuable Complement to Traditional Economic Indicators but Are Not yet Ready to Compete with Them." Behavioural Public Policy 4 (2): 198-209.

Ben-Shahar, Omri. 2016. "The Paradox of Access Justice, and Its Application to Mandatory Arbitration." University of Chicago Law Review 83 (4): 1755-1818.

Ben-Shahar, Omri, and Carl E Schneider. 2011. "The Failure of Mandated Disclosure." University of Pennsylvania Law Review 647: 103.

Berkouwer, Susanna, and Joshua Dean. 2020. "Credit and Attention in the Adoption of Profitable Energy Efficienttechnologies in Kenya."

Bernheim, Douglas, and Dmitry Taubinsky. 2018. "Behavioral Public Economics." In Handbook of Behavioral Economics: Applications and Foundations 1, edited by B. Douglas Bernheim, Stefano DellaVigna, and David Laibson, 1:381-516. North-Holland.

Bertrand, Marianne, and Esther Duflo. 2017. "Field Experiments on Discrimination." In Handbook of Field Experiments, edited by Abhijit Banerjee and Esther Duflo. Vol. 2. North-Holland. https://ideas.repec.org/p/nbr/nberwo/22014.html.

Bertrand, Marianne, Dean Karlan, Sendhil Mullainathan, Eldar Shafir, and Jonathan Zinman. 2010. "What's Advertising Content Worth? Evidence from a Consumer Credit Marketing Field Experiment." Quarterly Journal of Economics 125 (1): 263-305.

Bertrand, Marianne, and Adair Morse. 2011. "Information Disclosure, Cognitive Biases, and Payday Borrowing." The Journal of Finance 66 (6): 1865-93.

Beshears, John, James J. Choi, David Laibson, and Brigitte C. Madrian. 2018. "Behavioral Household Finance." In Handbook of Behavioral Economics: Applications and Foundations 1, edited by B. Douglas Bernheim, Stefano DellaVigna, and David Laibson, 1:177-276. Handbook of Behavioral Economics - Foundations and Applications 1. North-Holland.

Bharadwaj, Prashant, William Jack, and Tavneet Suri. 2019. "Fintech and Household Resilience to Shocks: Evidence from Digital Loans in Kenya." NBER working paper 25604. NBER. https://www.nber.org/papers/w25604.

Bird, Matthew, K. Longman, and Rafe Mazer. 2020. "Complaints Data as a Tool for Consumer Protection: Lessons from Uganda.” November 25. https://www.povertyaction.org/sites/default/files/presentation/IPA\%20Uganda\%20Complaints\%20Data\%20Analysis \%20Webinar\%20-\%20Bird\%20-\%2020201125.pdf.

Björkegren, Daniel, and Darrell Grissen. 2018. "The Potential of Digital Credit to Bank the Poor." AEA Papers and Proceedings 108: 68-71.

Bohren, J. Aislinn, Kareem Haggag, Alex Imas, and Devin G. Pope. 2019. "Inaccurate Statistical Discrimination: An Identification Problem." National Bureau of Economic Research Working Paper 25935 (June).

Bordalo, Pedro, Katherine Coffman, Nicola Gennaioli, and Andrei Shleifer. 2016. "Stereotypes." The Quarterly Journal of Economics 131 (4): 1753-94.

Breza, Emily, Martin Kanz, and Leora Klapper. 2020. "Learning to Navigate a New Financial Technology: Evidence from Payroll Accounts." National Bureau of Economic Research Working Paper, Working Paper, 28249 (December).

Breza, Emily, and Cynthia Kinnan. 2020. "Measuring the Equilibrium Impacts of Credit: Evidence from the Indian Microfinance Crisis." 
Brown, Rachel, Jim Larson, Boriwat Pinpradab, and Shalini Unnikrishnan. 2019. "How Mobile Money Agents Can Expand Financial Inclusion." Boston, MA: Boston Consulting Group. https://www.bcg.com/en-us/publications/2019/how-mobile-money-agents-can-expand-financialinclusion.

Buku, Mercer, and Rafe Mazer. 2017. "Fraud in Mobile Financial Services: Protecting Consumers, Providers, and the System." CGAP Brief, April.

Burke, Jeremy, Julian Jamison, Dean Karlan, Kata Mihaly, and Jonathan Zinman. 2020. "Credit Building or Credit Crumbling? A Credit Builder Loan's Effects on Consumer Behavior, Credit Scores and Their Predictive Power."

Burke, Jeremy, Christine N. Kieffer, Gary R. Mottola, and Francisco Pérez-Arce. 2020. "Can Educational Interventions Reduce Susceptibility to Financial Fraud?," December.

Burlando, Alfredo, Michael Kuhn, and Silvia Prina. 2020. "Digital Credit Delivery Speed and Repayment Rates."

Busso, Matias, and Sebastian Galiani. 2014. "The Causal Effect of Competition on Prices and Quality: Evidence from a Field Experiment." Cambridge, MA.

Callen, Michael, Mohammad Isaqzadeh, James D Long, and Charles Sprenger. 2014. "Violence and Risk Preference: Experimental Evidence from Afghanistan." The American Economic Review 104 (1): $123-48$.

Campbell, John. 2016. "Restoring Rational Choice: The Challenge of Consumer Financial Regulation." American Economic Review 106 (5): 1-30.

Campbell, John, Howell E Jackson, Brigitte C Madrian, and Peter Tufano. 2011. "Consumer Financial Protection." The Journal of Economic Perspectives 25 (1): 91-113.

Carvalho, Leandro, Arna Olafsson, and Dan Silverman. 2020. "Misfortune and Mistake: The Financial Conditions and Decision-Making Ability of High-Cost Loan Borrowers."

Castri, Simone di, Matt Grasser, and Arend Kulenkampff. 2019. "A Chatbot Application and Complaints Management System for the Bangko Sentral Ng Pilipinas (BSP) R2A Project Retrospective and Lessons Learned." Bank for International Settlements.

CFPB. 2017. "Measuring Financial Well-Being: A Guide to Using the CFPB Financial Well-Being Scale." Washington, DC: Consumer Financial Protection Bureau. https://www.consumerfinance.gov/data-research/research-reports/financial-well-being-scale/.

Chandrasekhar, Arun G., Horacio Larreguy, and Juan Pablo Xandri. 2020. "Testing Models of Social Learning on Networks: Evidence From Two Experiments.” Econometrica 88 (1): 1-32.

Chapman, Jonathan, Erik Snowberg, Stephanie Wang, and Colin Camerer. 2019. "Loss Attitudes in the U.S. Population: Evidence from Dynamically Optimized Sequential Experimentation (DOSE)."

Charles, Kerwin Kofi, and Jonathan Guryan. 2011. "Studying Discrimination: Fundamental Challenges and Recent Progress." Annual Review of Economics 3 (1): 479-511.

Chetty, Raj. 2015. "Behavioral Economics and Public Policy: A Pragmatic Perspective." American Economic Review 105 (5): 1-33.

Cole, Shawn, and Yannick Saleman. 2015. "SKS and the AP Microfinance Crisis." Harvard Business School Case 212-018. Harvard Business School. https://www.hbs.edu/faculty/Pages/item.aspx?num=41007.

Corbett-Davies, Sam, and Sharad Goel. 2018. "The Measure and Mismeasure of Fairness: A Critical Review of Fair Machine Learning." ArXiv:1808.00023 [Cs], August. http://arxiv.org/abs/1808.00023.

Crouzet, Nicolas, Apoorv Gupta, and Filippo Mezzanotti. 2020. "Shocks and Technology Adoption: Evidence from Electronic Payment Systems." In FinTech: Adoption and Consequences. San Diego, CA. https://www.aeaweb.org/conference/2020/preliminary/2033?q=eNqrVipOLS7OzM8LqSxIVbKq hnGVrJQMlWp11BKLi_OTgRwlHaWS1KJcXAgrJbESKpSZmwphlWWmloO0FxUUXDAFTA 1AegsS01Mh5lwwXDBunx4U. 
Cuesta, J., and Alberto Sepúlveda. 2019. "Price Regulation in Credit Markets: A Trade-Off between Consumer Protection and Credit Access." Working Paper.

D’Acunto, Francesco, and A.G. Rossi. 2021. "Robo-Advising." In Palgrave Handbook of Technological Finance, edited by Raghavendra Rau, Robert Wardrop, and Luigi Zingales, 1st ed. Palgrave Macmillan.

Davidson, Neil, and Paul Leishman. 2012. "Building, Incentivising and Managing a Network of Mobile Money Agents: A Handbook for Mobile Network Operators." GSMA. gsma.com/mobilefordevelopment/wp-content/uploads/2011/02/Agent-Networks-full.pdf.

De Giorgi, Giacomo, Andres Drenik, and Enrique Seira. 2020. "The Extension of Credit and Sequential Banking Externalities."

Demirgüç-Kunt, Asli, Baybars Karacaovali, and Luc Laeven. 2005. "Deposit Insurance around the World : A Comprehensive Database." World Bank Policy Research Working Paper 3628 (June). https://openknowledge.worldbank.org/bitstream/handle/10986/8226/wps36280rev.pdf?sequence= $1 \&$ isAllowed $=\mathrm{y}$.

Demirgüç-Kunt, Asli, Leora Klapper, Dorothe Singer, Saniya Ansar, and Jake Hess. 2017. "The Global Findex Database 2017: Measuring Financial Inclusion and the Fintech Revolution." World Bank Policy Research Working Paper.

Demirgüç-Kunt, Asli, Leora Klapper, Dorothe Singer, and Peter Van Oudheusden. 2015. "The Global Findex Database 2014: Measuring Financial Inclusion around the World." World Bank Policy Research Working Paper 7255.

Di Maggio, Marco, Ankit Kalda, and Vincent Yao. 2020. "Second Chance: Life without Student Debt."

Dobbie, Will, Andres Liberman, Daniel Paravisini, and Vikram Pathania. forthcoming. "Measuring Bias in Consumer Lending." The Review of Economic Studies. https://www.restud.com/paper/measuring-bias-in-consumer-lending/.

Dobbie, Will, and Jae Song. 2015. "Debt Relief and Debtor Outcomes: Measuring the Effects of Consumer Bankruptcy Protection." The American Economic Review 105 (3): 1272-1311. 2020. "Targeted Debt Relief and the Origins of Financial Distress: Experimental Evidence from Distressed Credit Card Borrowers." American Economic Review 110 (4): 984-1018.

Donnelly, Grant, Cait Lamberton, Stephen Bush, Zoe Chance, and Michael Norton. 2020. "'Repaymentby-Purchase' Helps Consumers to Reduce Credit Card Debt."

Duarte, Fabian, and Justine S. Hastings. 2012. "Fettered Consumers and Sophisticated Firms: Evidence from Mexico's Privatized Social Security Market.” NBER Working Paper w18582. National Bureau of Economic Research.

Dupas, Pascaline, Sarah Green, Anthony Keats, and Jonathan Robinston. 2016. "Challenges in Banking the Rural Poor Evidence from Kenya's Western Province.” In African Successes, Volume III: Modernization and Development, edited by Sebastian Edwards, Simon Johnson, and David N. Weil, 63-101. National Bureau of Economic Research. Chicago ; London: The University of Chicago Press.

Dupas, Pascaline, Dean Karlan, Jonathan Robinson, and Diego Ubfal. 2018. "Banking the Unbanked? Evidence from Three Countries." American Economic Journal: Applied Economics 10 (2): 25797.

EFInA. 2018. "Access to Financial Services in Nigeria Survey.” Lagos, Nigeria: EFInA. https://www.efina.org.ng/our-work/research/access/.

Ellison, Glenn, and Sara Fisher Ellison. 2009. "Search, Obfuscation, and Price Elasticities on the Internet." Econometrica 77 (2): 427-52.

Estache, Antonio, and Liam Wren-Lewis. 2009. "Toward a Theory of Regulation for Developing Countries: Following Jean-Jacques Laffont's Lead.” Journal of Economic Literature 47 (3): 729 70.

Fekrazad, Amir. 2020. "Impacts of Interest Rate Caps on the Payday Loan Market: Evidence from Rhode Island.” Journal of Banking \& Finance 113 (April): 105750. 
Ferrari, Aurora, Oliver Masetti, and Jiemin Ren. 2018. "Interest Rate Caps: The Theory and the Practice." World Bank Policy Research Paper 8398. Washington DC: World Bank. https://openknowledge.worldbank.org/handle/10986/29668.

FSD Kenya. 2019. "The 2019 FinAccess Household Survey - Financial Sector Deepening Kenya." Nairobi, Kenya: FSD Kenya. https://fsdkenya.org/publication/finaccess2019/.

Fuster, Andreas, Paul Goldsmith-Pinkham, Tarun Ramadorai, and Ansgar Walther. 2020. "Predictably Unequal? The Effects of Machine Learning on Credit Markets."

Gabaix, Xavier. 2019. "Behavioral Inattention." In Handbook of Behavioral Economics- Foundations and Applications 2, Volume 2, edited by Douglas Bernheim, Stefano DellaVigna, and David Laibson. Elsevier.

Gabaix, Xavier, and David Laibson. 2006. "Shrouded Attributes, Consumer Myopia, and Information Suppression in Competitive Markets." Quarterly Journal of Economics 121 (2): 505-40.

Gabaix, Xavier, David Laibson, Deyuan Li, Hongyi Li, Sidney Resnick, and Casper G. de Vries. 2016. "The Impact of Competition on Prices with Numerous Firms." Journal of Economic Theory 165 (September): 1-24.

Galenianos, Manolis, and Alessandro Gavazza. 2019. "Regulatory Interventions in Consumer Financial Markets: The Case of Credit Cards." 13807. CEPR Discussion Papers. CEPR Discussion Papers. C.E.P.R. Discussion Papers. https://ideas.repec.org/p/cpr/ceprdp/13807.html.

Galiani, Sebastian, Paul Gertler, and Camila Navajas-Ahumada. 2020. "Trust and Saving in Financial Institutions by the Poor." Working Paper, June. https://acsweb.ucsd.edu/ cnavajas/pdfs/Trust_and_Savings.pdf.

Giné, Xavier, Cristina Martínez Cuellar, and Rafael Keenan Mazer. 2017. "Information Disclosure and Demand Elasticity of Financial Products : Evidence from a Multi-Country Study." 8210. Policy Research Working Paper Series. Policy Research Working Paper Series. Washington, DC: The World Bank. https://ideas.repec.org/p/wbk/wbrwps/8210.html.

Giné, Xavier, and Rafael Keenan Mazer. 2021. "Financial (Dis-)Information: Evidence from a MultiCountry Audit Study."

Gomes, Francisco, Michael Haliassos, and Tarun Ramadorai. forthcoming. "Household Finance.” Journal of Economic Literature.

Greenwood, Robin, and David Scharfstein. 2013. "The Growth of Finance.” Journal of Economic Perspectives 27 (2): 3-28.

Grubb, Michael. 2015. "Failing to Choose the Best Price: Theory, Evidence, and Policy." Review of Industrial Organization 47 (3): 303-40.

GSMA. 2020. “The Mobile Gender Gap Report 2020.” London, UK: GSMA. https://www.gsma.com/r/gender-gap/.

Gubbins, Paul. 2019. "Digital Credit in Kenya: Facts and Figures from FinAccess 2019." Nairobi, Kenya: FSD Kenya. https://fsdkenya.org/publication/focus-note-digital-credit-in-kenya/.

Haendler, Charlotte, and Rawley Heimer. 2021. "The Financial Restitution Gap in Consumer Finance: Insights from Complaints Filed with the CFPB."

Hastings, Justine, Ali Hortaçsu, and Chad Syverson. 2017. "Sales Force and Competition in Financial Product Markets: The Case of Mexico's Social Security Privatization.” Econometrica 85 (6): 1723-61.

Heidhues, Paul, and Botond Köszegi. 2018. "Behavioral Industrial Organization.” In Handbook of Behavioral Economics: Applications and Foundations 1, edited by Douglas Bernheim, Stefano DellaVigna, and David Laibson, 1:517-612. Elsevier.

Higgins, Sean. 2020. "Financial Technology Adoption." Northwestern University Working Paper.

Hofstetter, Marc, Daniel Mejía, José Nicolás Rosas, and Miguel Urrutia. 2018. "Ponzi Schemes and the Financial Sector: DMG and DRFE in Colombia." Journal of Banking \& Finance 96 (November): $18-33$. 
Horn, Samantha, Julian Jamison, Dean Karlan, and Jonathan Zinman. 2020. "Does Lasting Behavior Change Require Knowledge Change? Evidence from Savings Interventions for Young Adults." Working Paper.

Izaguirre, Juan Carlos. 2020. "Making Consumer Protection Regulation More Customer-Centric." Working Paper. Washington, D.C.: CGAP.

Jayachandran, Seema. 2015. "The Roots of Gender Inequality in Developing Countries." Annual Review of Economics 7 (1): 63-88.

Johnson, Eric J., Stephan Meier, and Olivier Toubia. 2019. "What's the Catch? Suspicion of Bank Motives and Sluggish Refinancing." The Review of Financial Studies 32 (2): 467-95.

Kaiser, Tim, Annamaria Lusardi, Lukas Menkhoff, and Carly Urban. 2020. "Financial Education Affects Financial Knowledge and Downstream Behaviors."

Kantar InterMedia. 2016. "Financial Inclusion Insights Data 2016." Washington, DC: Kantar Intermedia. http://finclusion.org/data_fiinder/.

Karlan, Dean, Sendhil Mullainathan, and Benjamin N. Roth. 2019. "Debt Traps? Market Vendors and Moneylender Debt in India and the Philippines." American Economic Review: Insights 1 (1): 27 42.

Karlan, Dean, Adam Osman, and Jonathan Zinman. 2019. "Dangers of a Double-Bottom Line: A Poverty Targeting Experiment Misses Both Targets."

Karlan, Dean, Aishwarya Lakshmi Ratan, and Jonathan Zinman. 2014. "Savings by and for the Poor: A Research Review and Agenda." Review of Income and Wealth 60 (1): 36-78.

Karlan, Dean, and Jonathan Zinman. 2010. "Expanding Credit Access: Using Randomized Supply Decisions to Estimate the Impacts." Review of Financial Studies 23 (1): 433-64. . 2018. "Long-Run Price Elasticities of Demand for Credit: Evidence from a Countrywide Field Experiment in Mexico." The Review of Economic Studies, September.

Kremer, Michael, Gautam Rao, and Frank Schilbach. 2019. "Chapter 5 - Behavioral Development Economics." In Handbook of Behavioral Economics: Applications and Foundations 1, edited by B. Douglas Bernheim, Stefano DellaVigna, and David Laibson, 2:345-458. Handbook of Behavioral Economics - Foundations and Applications 2. North-Holland.

Laibson, David, Peter Maxted, and Benjamin Moll. 2020. "Present Bias Amplifies the Household Balance-Sheet Channels of Macroeconomic Policy."

Laibson, David, Andrea Repetto, and Jeremy Tobacman. 2020. "Estimating Discount Functions with Consumption Choices Over the Lifecycle."

Li, Danielle, Lindsey Raymond, and Peter Bergman. 2020. "Hiring as Exploration." National Bureau of Economic Research Working Paper 27736 (August).

Loewenstein, George, Cass R. Sunstein, and Russell Golman. 2014. "Disclosure: Psychology Changes Everything." Annual Review of Economics 6 (1): 391-419.

Lusardi, Annamaria, and Carlo de Bassa Scheresberg. 2013. "Financial Literacy and High-Cost Borrowing in the United States." w18969. National Bureau of Economic Research.

Lusardi, Annamaria, and Peter Tufano. 2015. "Debt Literacy, Financial Experiences, and Overindebtedness." Journal of Pension Economics \& Finance 14 (4): 332-68.

Maimbo, Samuel Munzele, and Claudia Alejandra Henriquez Gallegos. 2014. "Interest Rate Caps around the World: Still Popular, but a Blunt Instrument." The World Bank.

Matiwane, Zimasa. 2019. "EFF Calls for Probe into 'racism by Banks' after Television Exposé." Times Live South Africa, March 12, 2019. https://www.timeslive.co.za/politics/2019-03-12-eff-calls-forprobe-into-racism-by-banks-after-television-expos/.

Mazer, Rafe, and Dan Onchieku. 2019. "Did You See My Tweet? Monitoring Financial Consumer Protection via Social Media." Nairobi, Kenya: FSD Kenya. https://fsdkenya.org/publication/didyou-see-my-tweet-monitoring-financial-consumer-protection-via-social-media/.

Meager, Rachael. 2019. "Understanding the Average Impact of Microcredit Expansions: A Bayesian Hierarchical Analysis of Seven Randomized Experiments." American Economic Journal: Applied Economics 11 (1): 57-91. 
2020. "Aggregating Distributional Treatment Effects: A Bayesian Hierarchical Analysis of the Microcredit Literature."

Meier, Stephan, and Charles Sprenger. 2010. "Present-Biased Preferences and Credit Card Borrowing." American Economic Journal: Applied Economics 2 (1): 193-210.

Mian, Atif, and Amir Sufi. 2018. "Finance and Business Cycles: The Credit-Driven Household Demand Channel." Journal of Economic Perspectives 32 (3): 31-58.

Montoya, Ana María, Eric Parrado, Alex Solís, and Raimundo Undurraga. 2020. "Bad Taste: Gender Discrimination in the Consumer Credit Market." Inter-American Development Bank.

Morawczynski, Olga. 2015. "Fraud in Uganda: How Millions Were Lost to Internal Collusion." CGAP Blog, March.

Morse, Adair, and Karen Pence. 2020. "Technological Innovation and Discrimination in Household Finance." Finance and Economics Discussion Series 2020 (February).

Mowl, Amy Jenson, and Camille Boudot. 2015. "Barriers to Basic Banking: Results from an Audit Study in South India." IMFR and NSE. https://ifmrlead.org/barriers-to-basic-banking-results-from-anaudit-study-in-south-india/.

Muris, Timothy J. 2002. "The Interface of Competition and Consumer Protection." Presented at the Fordham Corporate Law Institute's Twenty-Ninth Annual Conference on International Antitrust Law and Policy, New York City, October 31.

https://www.ftc.gov/sites/default/files/documents/public_statements/interface-competition-andconsumer-protection/021031 fordham.pdf.

Pandey, Akshat, and Aylin Caliskan. 2020. "Iterative Effect-Size Bias in Ridehailing: Measuring Social Bias in Dynamic Pricing of 100 Million Rides.” ArXiv:2006.04599 [Cs], June. http://arxiv.org/abs/2006.04599.

Pennycook, Gordon, and David Gertler Rand. 2020. "The Cognitive Science of Fake News.” Preprint. PsyArXiv.

Rysman, Marc. 2009. "The Economics of Two-Sided Markets." Journal of Economic Perspectives 23 (3): 125-43.

Sadka, Joyce, Enrique Seira, and Christopher Woodruff. 2018. "Information and Bargaining through Agents: Experimental Evidence from Mexico's Labor Courts.” w25137. Cambridge, MA: National Bureau of Economic Research.

Sambasivan, Nithya, Amna Batool, Nova Ahmed, Tara Matthews, Kurt Thomas, Laura Gaytan-Lugo, David Nemer, Elie Bursztein, and Sunny Consolvo. 2019. ""They Don't Leave Us Alone Anywhere We Go": Gender and Digital Abuse in South Asia." Proceedings of the 2019 CHI Conference on Human Factors in Computing Systems, Glasgow Scotland, May. https://storage.googleapis.com/pub-tools-public-publicationdata/pdf/acf12158ab313c1e9d80b87ede065254f64ad9a7.pdf.

Sapienza, Paola, and Luigi Zingales. 2012. "A Trust Crisis.” International Review of Finance 12 (2): 123-31.

Schechter, Laura. 2007. "Traditional Trust Measurement and the Risk Confound: An Experiment in Rural Paraguay." Journal of Economic Behavior \& Organization 62 (2): 272-92.

Schmulow, Andrew. 2020. "Consumer Financial Well-Being in South Africa's Twin Peaks Regulatory Regime: From Measurement, to Confidence in Outcomes." International Review of Financial Consumers 5 (2): 1-11.

Seira, Enrique, Alan Elizondo, and Eduardo Laguna-Müggenburg. 2017. “Are Information Disclosures Effective? Evidence from the Credit Card Market." American Economic Journal: Economic Policy 9 (1): 277-307.

Singh, Anubhutie, and Srikara Prasad. 2020. "Artificial Intelligence in Digital Credit in India." Dvara Research Blog (blog). April 13, 2020. https://www.dvara.com/blog/2020/04/13/artificialintelligence-in-digital-credit-in-india/. 
Singh, Mahendra. 2017. "Rs 167cr Deposited in Airtel Bank without 'Consent' of 31L Users." The Times of India, December 18, 2017. https://timesofindia.indiatimes.com/business/india-business/rs167cr-deposited-in-airtel-bank-without-consent-of-311-users/articleshow/62111310.cms.

Skiba, Paige, and Jeremy Tobacman. 2018. "Payday Loans, Uncertainty, and Discounting: Explaining Patterns of Borrowing, Repayment, and Default.” Working paper. Vanderbilt University, Nashville TN.

Stango, Victor, and Jonathan Zinman. 2009. "Exponential Growth Bias and Household Finance." The Journal of Finance 64 (6): 2807-49.

- 2011. "Fuzzy Math, Disclosure Regulation, and Credit Market Outcomes: Evidence from Truthin-Lending Reform." Review of Financial Studies 24 (2): 506-34.

- 2020a. "Behavioral Biases Are Temporally Stable."

- 2020b. "We Are All Behavioral, More or Less: A Taxonomy of Consumer Decision Making."

Suri, Tavneet. 2017. "Mobile Money." Annual Review of Economics 9 (1): 497-520.

Tarozzi, Alessandro, Aprajit Mahajan, Brian Blackburn, Dan Kopf, Lakshmi Krishnan, and Joanne Yoong. 2014. "Micro-Loans, Insecticide-Treated Bednets, and Malaria: Evidence from a Randomized Controlled Trial in Orissa, India." American Economic Review 104 (7): 1909-41.

Temin, Peter, and Hans-Joachim Voth. 2008. "Interest Rate Restrictions in a Natural Experiment: Loan Allocation and the Change in the Usury Laws in 1714." The Economic Journal 118 (528): $743-$ 58.

Tirole, Jean, and Steven Rendall. 2017. Economics for the Common Good. Princeton University Press.

Toronto Centre. 2019. "Supervising Fintech to Promote Financial Inclusion." TC Notes. Toronto, ON, Canada: Toronto Centre.

https://res.torontocentre.org/guidedocs/Supervising\%20FinTech\%20to\%20Promote\%20Financial $\% 20$ Inclusion.pdf.

Tully, Melissa, and Dani Madrid-Morales. 2020. "Social Media as a Tool for Consumer Protection Monitoring." Presented at the Innovations for Poverty Action Consumer Protection Practitioner's Forum, September 29. https://www.poverty-action.org/event/ipas-consumer-protection-researchinitiative-holds-first-practitioner\%E2\%80\%99s-forum-meeting.

Waldman, Ari Ezra. 2018. Privacy as Trust: Information Privacy for an Information Age. 1st ed. Cambridge University Press.

West, Jarrod, and Maumita Bhattacharya. 2016. "Intelligent Financial Fraud Detection: A Comprehensive Review.” Computers \& Security 57 (March): 47-66.

World Bank. 2017. "Global Financial Inclusion and Consumer Protection Survey, 2017 Report." Washington, DC: World Bank.

2019. "Global ID Coverage, Barriers, and Use by the Numbers : An In-Depth Look at the 2017

ID4D-Findex Survey." Washington, DC: World Bank. https://openknowledge.worldbank.org/handle/10986/33430.

World Bank Group. 2017. "Good Practices for Financial Consumer Protection.” Washington DC: World Bank.

Zinman, Jonathan. 2014. “Consumer Credit: Too Much or Too Little (or Just Right)?” Journal of Legal Studies 43 (S2 Special Issue on Benefit-Cost Analysis of Financial Regulation): S209-37. 2015. "Household Debt: Facts, Puzzles, Theories, and Policies." Annual Review of Economics 7 (1): 251-76. 